\title{
The social (and cultural, and syntactic, and semantic) life of generics
}

\author{
B R U C E M A N N H E I M \\ University of Michigan, USA
}

\section{A B S T R A C T}

\begin{abstract}
Recent work in linguistics, philosophy, and psychology suggests that the distinction between generic and specific (singular) reference is foundational to concept formation, and hence of special interest to social scientists. Generics provide the first-language learner with external evidence of the integrity of a word/concept cluster, partially filling in the scaffolding of concepts. As such, they are replicators, critical to the transmission of concepts across populations and across time. Generics are tacitly normative. As they refer to the constitutive properties of a concept rather than to its object, they tell us what - in a given social setting - a proper instance of the concept should look like. Generics sustain and reproduce social stereotypes, including - and perhaps especially-ethnoracial, class, and gender stereotypes. (Generics, conceptual formation, ethnography, tokenization, materiality)*
\end{abstract}

\section{N T R O D U C T I O N}

Generics are at the nexus of semantics, grammar, and culture. Recent work in several fields - sometimes carried out in relative isolation one field from the other-suggests that the distinction between generic and specific (singular) reference is foundational to concept formation, and hence of special interest to social scientists, broadly speaking (Carlson \& Pelletier 1995; Prasada 2000; Gelman 2003; Leslie 2008; McConnell-Ginet 2012). The arguments adduced by these psychologists, linguists, and philosophers refute an alternative, that generics - and more generally, type concepts - are adduced from specifics, by generalizing them, or typification. Generics do not involve generalizations from experience; rather they are normative structures, at once filling in conceptual placeholders and projecting them into the social world. Familiar examples, discussed by Gelman (this issue) show that generic expressions frequently contravene evidence from experience. Generic utterances are universal, though likely in no language is there a single, dedicated generic syntactic construction. On the experimental evidence discussed by Gelman and her colleagues, genericity is rather the default interpretation of a noun or noun phrase and requires additional syntactic and pragmatic specification to become concrete and specific. 
Generics (and 'characterizing utterances' - essentially verb-based generics) are abstract; point to semantic types rather than semantic individuals; point to core properties of the category being described, as enduring, timeless, inherent (not accidental); are normative, and potentially regiment meaning (and ontology). As a consequence, generics are social replicators, mechanisms by which social knowledge spreads across communities (Sperber 1985; Enfield 2007), much as are grammatical categories (Hill \& Mannheim 1992; Lucy 1997) and structural alignment (Mannheim 1984, 1998:267-68; Markman \& Gentner 1997; Gentner \& Medina 1998) below the threshold of awareness, and metapragmatics (Lucy 1993; Silverstein 1993) and linguistic ideology (Woolard 1998; Gal \& Irvine 2019:167-89) above. ${ }^{1}$ As cognitive and linguistic substructures, genericity can be recruited to UNDERWRITE SOCIAL ESSENTIALISM AND STEREOTYPES (especially with respect to 'ethnicity' and gender, 'language's way of letting us give voice to cognitively primitive generalizations' (Leslie 2017:395). My task in this article is to discuss general properties of generics and to explain why a clear and consistent distinction between generic and specific utterances is fundamental to social analysis and ethnographic interpretation. Along with English, a substantial portion of my examples comes from Southern Peruvian Quechua, a language and culture that I have been working on, and with, for several decades.

\section{GENERICS IDENTIFY CONCEPTS AS INTEGRAL E N T I T I E S}

Since the mid 1980s, cognitive psychologists have adduced evidence that concepts emerge from more general and broad knowledge that people have about the world. They are not atomistic 'building blocks' of thought (Keane 2006); rather, from the very beginning they are embedded in overarching theories (e.g. Murphy \& Medin 1985; Gelman \& Coley 1991; Keil 1991; Gopnik \& Wellman 1994; Simons \& Keil 1995; R. Gelman \& Williams 1998; Wellman \& Gelman 1998; Carey 2009; Gelman, Mannheim, Escalante, \& Sánchez Tapia 2015; see Gelman, this issue). These tacit theories, embedded in domains, establish ontologies, causal relationships, and unobservable entities specific to the domains. From this point of view, the early acquisition of concepts is not strictly perceptual in origin but is tethered to broader ontological configurations (for example, a distinction between animate and inanimate entities delineated grammatically, or a hierarchy of agentivity configured by grammatical agreement properties of classes of nouns; Silverstein 1976) and to expectations regarding the causal laws of which the concepts are part (for example, a dog is initially classified an agent capable of autonomous movement). The tacit theories that scaffold concept formation are specific to domains (psychology, biology, physics, and so forth) and have domain-specific object-ontologies built into them (Mannheim 2020), and these are, in turn, attributed to the kinds subsumed by them. 
Central to this account are several observations: that there is a disjunction between appearances and underlying realities, the underlying realities bound to an ontological configuration (the 'domain'), so that the construal of an underlying reality is domain specific; and kinds have underlying conceptual essences (Gelman 2003). The domains act as conceptual scaffolding, linking a minimally specified concept into a conceptual assemblage — an intuitive theory — that affords inferences about the concept from minimal external evidence. Along with a core set of domains that resemble each other from language to language and culture to culture, some domains are distinctly different across cultures. For example, a two-way distinction between social persons and wild beings for most indigenous lowland South Americans as opposed to a three-way distinction including domestic species for Euroamericans or for indigenous HIGHLAND South Americans. ${ }^{2}$ Recruitment of a concept to a domain can also vary cross-culturally. For example, for Southern Quechuas, ${ }^{3}$ places are social beings, endowed with sentience and speech, and enter into long-terms social relationships with humans and with domestic animals, mediated by reciprocal feeding (Mannheim \& Salas Carreño 2015; Salas Carreño 2019). Similarly, while rock and qaqa refer to the same set of objects for American English and Southern Quechua speakers, Quechua qaqa flows (as it does for American English-speaking geologists). Qaqa is underspecified by the domain, but is filled out materially and in verbal art. The Inka ancestors of modern Quechua speakers landscaped moving water with rock-marking water sources and water flows with stepped fret designs around portals carved into living stone, which can be activated either by water flowing through them or by liquid being poured on them-a motif found at multiple Inka sites, not figurations of water but indexes that signal the ontic bind between mayu and qaqa as substances (Dean 2010; Cummins \& Mannheim 2011). So too was rock inscribed as flowing water: In Machu Pikchu, living stone was carved into tapered fissures, crossing agricultural terraces, so as to flow across the mountainside as rushing river would, flowing toward the Urubamba River below (Cummins \& Mannheim 2011:7).

The modern-day descendants of the Inkas take up the connection between river and rock in popular song - a waynu — from the 1960s, Urpischallay, the singer, asks:

(1) Maytaq chay munakusqayki

Maytaq chay wayllukusqayki

'But where is your desire (munakusqa)?

But where is your affection (wayllukusqa)?'

And then asserts:

(2) Mayullawaqchá aparachiwanki

Qaqallawaqchá ñit'irachiwanki

'Perhaps you've had river (mayu) carry me off

Perhaps you've had rock (qaqa) crush me'

Language in Society 50:4 (2021) 
This is not a one-off. A late twentieth-century Quechua smallholder might have heard word-pairings such as those above literally hundreds of times, the lyrics structured by paired semantic couplets. In the first couplet, the verb munay 'to want' is paired with the verb waylluy 'to care for, with shows of affection'. These are a semantic minimal pair in Quechua-they are as closely related to each other semantically as two words can be, with no third value coming between them (so no verb for 'slightly affectionate', for example). And in the second couplet, in which 'river' (mayu) pairs with 'rock' (qaqa)? These two are also a conceptual minimal pair, and the stem qaqa (rock as a substance) is, in turn, paired with rumi 'individuated stone'. The river/rock couplet is common in Quechua songs, and its patterning is no different from that of more transparent couplets such as munay 'want' and waylluy 'to care for with shows of affection'. These couplets entail specific ontic relationships among the objects that they denote and so project them-and the relationship between them - into the Quechua world. That mayu 'river' routinely pairs with qaqa 'rock' as things that flow is an everyday fact about the world rather than a poetic figure. This is as unremarkable to a rural Quechua speaker as a sunrise. As they fill in the conceptual placeholders for 'river' and 'rock' they are semantic replicators (Mannheim 1984), but there are two other properties that are especially relevant to the present discussion: semantically, the couplets are 'intensional contexts', in which the denotatum of an expression shifts from the conventional referent to the conceptual SENSE of the expression (classically observed by the philosopher Gottlob Frege_-see Mannheim 1987). Second, semantic couplets rarely co-occur with evidentials, which in Quechua means that they are (almost) never under syntactic focus, and (almost) always generic.

I return to that point below. For now, there are three key take-aways here. First, concepts are not labels for 'things' nor built up cumulatively from 'experience' but are always part of larger structures - domain-specific intuitive theories. Second, intuitive theory structures underspecify concepts (i.e. concepts have a placeholder structure; Medin \& Ortony 1989), which are filled in by externalities. And third, concepts and their expression in generics do not float freely in a disembodied conceptual or cultural system, but are intimately bound with the way the material world is understood and experienced. GENERICS IDENTIFY CONCEPTS AS INTEGRAL ENTITIES, AND SO PLAY A CRITICAL ROLE IN REPLICATING CONCEPTUAL STRUCTURES ACROSS COMMUNITIES OF SPEAKERS.

\section{THE VERY IDEA OF GENERICS}

Traditionally, generics were treated as generalizations from experience, essentially as defective universal quantifiers. But just as concepts are not built up cumulatively from experience, generics are not generalizations; rather they point to core properties of a concept. In this section, following Gelman (this issue), I distinguish generics from specifics and propose-along the lines of 
the emerging view of generics - that the default interpretation of noun phrases is generic, rather than specific; that semantically specific noun phrases consist of a generic plus additional phonological, syntactic, or pragmatic specification, and that consequently, generic meanings are never expressed by a single grammatical construction. ${ }^{4}$ To be sure, languages often have narrow-gauge generic constructions, such as the definite article plus bare noun construction in English, as in (3) below.

\section{(3) The lion is a friendly beast. (Lyons 1977)}

But this is a specialized construction that exists alongside the more common generics-as-default in English, pertaining to a specific register, with a pragmatics, semantics, syntax, and history of its own.

In my walk through the basic properties of generics, I draw on examples that appear in a cluster of recent publications by psychologists and philosophers, including Andrei Cimpian, Susan A. Gelman, Sarah-Jane Leslie, and others without further specifying the source. ${ }^{5}$

In the examples in (4), the italicized noun phrases are SPECIFIC in that they refer to specific individuals.
a. This dog was in an accident. It has three legs.
b. I don't want to take a nap.
c. The bread is delicious.

In contrast, the italicized noun phrases in (5) are GENERIC, in that they refer to semantic kinds rather than specific individuals. Notice that (5a) can be used felicitously even though there are dogs that do not have four legs, like the one in (4a), but that adding the quantifier 'most' would be pragmatically infelicitous because it suggests that the 'mostness' of having four legs is characteristic of dogs. Also notice that (5b) is predicated of a class, even though it was a single individual (a toddler) talking about himself. No noun is impervious to being deployed generically, including names, such as Adam or Cohen (Silverstein, this issue).

a. Dogs have four legs.

b. Adams don't have to take naps.

c. Bread is the staff of life.

Finally, the same kind of distinction can be made for events. These are characterizing utterances (Krifka, Pelletier, Carlson, ter Meulen, Chierchia, \& Link 1995:12). Consider the examples in (6).

a. I made a burnt offering to the place when my animals began to die.

b. When their animals die, Quechuas make a burnt offering to the place. 
Example (6a) is a specific utterance from my own ethnography in southern Peru (and from memory). Were I to follow up by explaining to a colleague that there is nothing idiosyncratic about the event described in (6a), I might add (6b), a characterizing utterance, in which the event described in (6b) is not only to be expected but is normative for Quechua smallholders (see Salas Carreño 2019), though I might rephrase it to avoid essentialist implications. But notice the slippage here. I have gone from a single instance of an event (a token, specific) to a typified statement (characterizing - that is, a generic event) without warranting its normativity, a slippage that is all-too-common in ethnographic analysis. In this case, the typified statement can be warranted by showing how the specific event (6a) is imbricated in an open network of practices that make appropriate the course of action described by (6b).

Moving from specific utterances like (6a) to characterizing utterances like (6b) is a substantial methodological problem in the social sciences. Consider a celebrated example, that of Bronisław Malinowski, an anthropologist who was stranded on the Trobriands during WWI, and is frequently credited with having invented modern ethnography. Malinowski famously enjoined would-be ethnographers to get down from the veranda and engage with everyday life. And so, in a publication on the Trobriands, Coral gardens and their magic (1935), followings a dense description of Kiriwinian (Trobriand) gardening Malinowski follows with a corpus of utterances putatively illustrating the practice itself of garden magic, arranged in small textlets with interspersed morpheme-by-morpheme translations (reformatted here for clarity), a free translation, and a brief discussion of each.

(7) T. 4. I-kalobusi-si mitawosi o buyagu, i-katupwo'i-se:

they arrive visitors in garden-site they ask:

'Avayle la buyagu?' 'O, ma-tau-na towosi'

who his garden-site $\mathrm{O}$ this man garden magician
'Avayta'u ma-kway-na bagula?' O, ma-tau-na,
which man this garden $\quad O$ this man
'bi-bagula la baleko'
he might garden his plot.

'When visitors arrive at a garden, they ask: "Whose garden enclosure is it?" "Oh, such and such is the garden magician." "Whose is this garden?" "Oh, such and such, he gardens his plot."” (Malinowski 1935:85).

Judging from the two translations, it is a characterizing utterance, not an instance of talk-in-context, but rather elicited, genericizing talk ABOUT talk-in-context. But what do we have here? Is the Kiriwinian speaker describing a routine that is normally followed by visitors to a garden even when they know perfectly well whose field it is, as an opening to other talk? Is the Kiriwinian speaker obliquely instructing the ethnographer as to a polite way of approaching a garden (and among other 
things, making certain that the ethnographer understand that he is just a short-term guest)? Or is it one of a myriad of other interpretive possibilities? Though Malinowski is careful to describe Kiriwinian gardening in considerable detail, so we have part of the open network of practices in print in front of us, in this case the surrounding discussion leaves us clueless as to how to understand (7). Because the move from specific to generic or from specific to characterizing utterance is a disappearing act, in which normative claims are introduced to ethnographic analysis, it is best used sparingly.

Under the generics-as-default hypothesis (Leslie 2007, 2012; Gelman 2010; Cimpian \& Erikson 2012; Leslie \& Lerner 2016), semantically specific noun phrases are derived from generics with added formal specification. The strongest candidate for 'added formal specification' is grammatical and semantic focus (Rooth 1995, 1996; van der Wal 2016). In English, this is achieved primarily by intonation and by constituent order. Consider the examples in (8) from Krifka (1995:239).

a. John only introduced [Bill $]_{\mathrm{F}}$ to Sue.

b. John only introduced Bill to $[\mathrm{Sue}]_{\mathrm{F}}$.

In Krifka's (1995:240) formulation, focus gives prominence to meaning-bearing elements in a sentence; elements under focus are non-generic. In ( $8 a)$ and $(8 b)$ focus is marked by sentence-level stress; the parts of each utterance under focus (marked with the subscript F) are being asserted; the parts of the utterance that are NOT under focus are presupposed.

In contrast, in Southern Peruvian Quechua, like other languages in the Quechua family, focus is marked by a small class of suffixes (usually called 'evidentials'), ${ }^{6}$ - $m i$ and $-s i$, that appear at the end of the focused syntactic constituent. Noun phrases within the syntactic scope of an evidential are specific; generics are marked by the ABSENCE rather than the PRESENCE of the linguistic markers (Mannheim et al. 2011:3-4). Quechua is an SOV (subject-object-verb) agglutinative language. It is a highly inflected, right-headed language with up to three to four suffixes on any noun and up to five to ten suffixes on any verb. In the context of this richly marked grammar, generics are unmarked morphologically, as they are expressed by the absence of specifying markers (such as tense or aspect on the verb), as in the song text discussed earlier.

Examples (9) and (10) illustrate the contrast between generics and non-generics in Quechua.

(9) Waka q'achuta mihun.

Waka q'achu-ta mihu-n.

Bovine forage-ACC eat-3

'Bovines eat forage.' 

(10) Wakaqa q'achutan mihushan watananpi.
Waka-qa q'achu-ta-n mihu-sha-n wata-na-n-pi.
Bovine-TOPIC forage-ACC-EVID eat-DURATIVE-3 tie-material.NOM-3POSS-LOC
'The cow is eating forage at its hitching post.'

Example (9) is generic, referring to bovines in general, not any particular cow or bull. Importantly, the morphological marking on this sentence is minimal-waka 'bovine' is bare and indeterminate as to number; $q$ 'achu 'forage' is marked only as the object of the verb; and mihu- 'to eat' is in the third person, with no tense, aspect, or number marking. In contrast, example (10) (from Cusihuamán Gutiérrez 1976:238) is non-generic, referring to a particular bovine that is tied to the hitching post. The utterance is marked with the evidential suffix -mi (here in its allomorph $-n$ ), making $q$ 'achu-ta 'forage' the focus of the utterance. The left boundary of the focus is marked by -qa on the subject waka. The verb mihu- 'to eat' is marked with the durative -sha, indicating that the action is ongoing (thereby marking aspect, though not tense). The specificity of the bovine is marked not only by saying that it is tied to the hitching post, but also by the additional grammatical morphemes (specifically, -sha, -mi, and -qa)-even though waka is not under focus itself. Generic expressions differ radically in their expression from English to Quechua, but they ultimately do the same work in both languages - that of identifying concepts and their quintessential properties.

So here's where we are (after Carlson \& Pelletier 1995; Prasada 2000; Gelman 2009; Cimpian \& Markman 2009): Generic expressions (and their characterizing counterparts) are abstract; point to semantic types rather than semantic individuals; point to core properties of the category being described, categories that are understood to be enduring (not transient), timeless (not contextually bound), and inherent (not accidental); are normative; and potentially regiment meaning (and ontology).

\section{K E Y F E A T U R E S}

To conclude, there are three key features of generics that make them of special interest to social scientists:

(i) Generics provide the first-language learner with external evidence of the integrity of a word/concept cluster, partially filling in the scaffolding of concepts. As such, they are replicators, critical to the transmission of concepts across populations and across time.

(ii) Generics are tacitly normative (Prasada \& Dillingham 2009; Orvell, Kross, \& Gelman 2017). As they refer to the constitutive properties of a concept rather than to its object, they tell us what - in a given social setting - a proper instance of the concept should look like. 
(iii) As such, generics sustain and reproduce social stereotypes, including - and perhaps especially - ethnoracial, class, and gender stereotypes. They are unavoidable to concept formation, but are at the same time vectors of especially pernicious social forms. And here Leslie (2017; also see McConnell-Ginet 2020:100-105) makes a striking proposal, that concepts and conceptual clusters for social kinds get a 'free ride' on the cognitive mechanisms that underwrite other conceptual domains. An 'appalling' (Leslie's expression) or otherwise striking social property or action attributed to as few as one member of an identifiable, essentialized social group can form the basis of a generic, which in turn licenses the property to be attributed to other individuals in the group. Notice that, like other generics, a social stereotype formed in this manner is impervious to falsification; the social stereotype cannot be rooted out by showing that it does not apply empirically in the absence of intimate familiarity, knowledge, and solidarity.

'As few as one member' or perhaps none at all. In the United States election campaign of 2020, one of the first responses of the then-sitting president was to characterize the opposition candidate for Vice President, Kamala Harris, as 'so angry'. Consider a recent report in the New York Times (August 14, 2020) that published a brief history of the trope, observing that the 'angry Black woman' stereotype has been attributed to Black women in public life, including to the tennis star, Serena Williams and to former First Lady of the United States Michele Obama, who described her hurt and bewilderment at the attribution. The persistence of the stereotype shows that the warrant of a generic need not be even a single angry woman, but that it can be sideloaded, the social image constructed from other, interconnected (and possibly empirically irrelevant) phenomena. ${ }^{7}$ Such attributions persist across time and space as they are successively applied in distinct social situations. Generic expressions permit cultural and linguistic features to be mobilized as indexes of membership in essentialized social groups (Gal \& Irvine 2019:39ff, 65ff).

\section{O N C L U S I O N}

In this article, I have concentrated on sketching a framework for considering linguistic generics as fundamental to ethnography and social analysis. In so doing, I have concentrated on the properties of generics as such, along with the mechanics of their expression. The failure to properly distinguish specifics from generics - and to work through their relationships in specific instances-has frequently led to a silent genericization of individual events and to ethnographic misrepresentation. I have suggested-along with scholars currently working in cognitive science - that while concepts are foundational to social engagement with the world, they are neither passive labels nor generalizations from experience. 
If I may put that in the form of a slogan, we need to attribute less to 'typification' (to use a Peircian term currently popular among linguistic anthropologists) and more on its converse, 'tokenization', in which concepts are deployed in real-time and real-world social interaction. Generics are key to conceptual formation and-as social replicators - to transmission, and so provide an exceptional window on the nature and development of cultural forms and a hinge to social development and social interaction. While my focus in this article is on the nature and workings of generics, it is critical to point out that in living cultures, in real-world settings, neither generic expressions nor their associated concepts are siloed; rather they are imbricated in open networks of concepts and in ongoing social interaction.

\section{N O T E S}

*For astute comments and questions at an oral presentation of this article, I am grateful to Judith T. Irvine and Joshua Shapero. I am indebted to Susan A. Gelman for her critical comments.

${ }^{1} \mathrm{~A}$ critical issue in practice-based approaches to culture and society is the 'coordination problem' (Goffman 1979; Lempert 2014; Mannheim 2018), that is specifying the conditions under which individual interactants coordinate social representations and build them into conventions (in the sense of Lewis 1969). I use the word replicator to refer to linguistic and social forms that have the semiotic properties that enable them to do so, regardless of whether they work tacitly or explicitly.

${ }^{2}$ This has evoked considerable discussion among anthropologists and historians of lowland South America, with substantial agreement among them. See Erickson 1987; Descola 1994; Fausto 1995; Norton 2015; and Costa 2017.

${ }^{3}$ 'Quechua' is a family of related languages, analogous to Romance. By 'Southern Peruvian Quechua', I mean the linguistic varieties spoken in the six southeastern Departments of Peru (i.e. Quechua sureño; Cerrón-Palomino 1987; Mannheim 1991, 2019; Adelaar \& Muysken 2004). In addition to geographic variability, distinct but overlapping registers of the language are spoken respectively by (i) monolinguals of rural origin, (ii) bilinguals with Spanish, of rural origin ((i) and (ii) both referenced locally as de comunidad), and (iii) urban bilinguals, often dominant in Spanish (Mannheim \& Huayhua 2016; Huayhua 2021). These varieties can be characterized by an overlapping lexicon and pragmatics, and a morphosyntax whose variability is as yet undetermined. When I refer to 'Southern Quechuas' and 'Southern Peruvian Quechuas' I refer primarily to individuals who speak the first two registers (de comunidad). The place of generics in the conceptual development of very young monolingual speakers of Southern Peruvian Quechua is discussed in Mannheim, Gelman, Escalante, Huayhua, \& Puma (2011).

${ }^{4}$ Generics are also the default mode of generalization. Developmentally, they precede precise quantifiers such as all. In experimental memory tasks, precise quantifiers are commonly remembered as generics, but not vice-versa (Leslie \& Gelman 2012).

${ }^{5}$ As these examples float across their publications - sometimes coauthored-I refer the reader to publications by these authors cited below.

${ }^{6}$ Older grammatical descriptions characterize 'evidentials' as marking a distinction between witnessed knowledge and reported knowledge, and Quechua languages have been (mistakenly) thought to manifest an evidential type in which the category directly indexes the speaker's source of knowledge. This is surely an oversimplification, as Quechua evidentials have been shown to distinguish a speaker's personal claim to authority when producing utterances that draw on encyclopedic ontic knowledge as opposed to personal knowledge (Faller 2002), assessments of mutual knowledge, recognition of the personal authority of an interlocutor, and the perspectival stance of the speaker. See Floyd (1999), Faller (2002), Nuckolls (2008), Howard (2014), and Hintz \& Hintz (2017) for discussions of the interactional pragmatics of evidentials in Quechua languages. 


\section{THE SOCIAL LIFE OF GENERICS}

${ }^{7}$ For a sociolinguistic example, see Candea (2017). Gal \& Irvine (2019:112-37) discuss the semiotic mechanisms by which such attributes are interconnected.

\section{R E F E R E N C E S}

Adelaar, Willem F. H., \& Pieter Muysken (2004). The languages of the Andes. Cambridge: Cambridge University Press.

Candea, Maria (2017). La notion d'« accent de banlieue » à l'épreuve du terrain. GlottopoL 29. Online: http://glottopol.univ-rouen.fr/numero_29.html\#tele/; accessed 1 March 2021.

Carey, Susan D. (2009). The origin of concepts. Oxford: Oxford University Press.

Carlson, Gregory N., \& Francis J. Pelletier (eds.) (1995). The generic book. Chicago: The University of Chicago Press.

Cerrón-Palomino, Rodolfo Marcial (1987). Lingüística quechua. Cuzco: Centro de Estudios Regionales Andinos 'Bartolomé de las Casas'.

Cimpian, Andrei, \& Lucy C. Erickson (2012). Remembering kinds: New evidence that categories are privileged in children's thinking. Cognitive Psychology 64(3):161-85.

_ \& Ellen M. Markman (2009). Information learned from generic language becomes central to children's biological concepts: Evidence from their open-ended explanations. Cognition 113:14-25.

Costa, Luiz (2017). Feeding animals and spirits: Kinship and history in Brazilian Amazonia. Chicago: University of Chicago Press for Hau Books.

Cummins, Thomas B. F., \& Bruce Mannheim (2011). The river around us, the stream within us, the traces of the Sun and Inka kinetics. Res 59/60:5-21.

Cusihuamán Gutiérrez, Antonio (1976). Gramática quechua, Cuzco-Callao. Lima: Instituto de Estudios Peruanos.

Dean, Carolyn (2010). A culture of stone: Inka perspectives on rock. Durham, NC: Duke University Press.

Descola, Philippe (1994). Pourquoi les Indiens d'Amazonie n'ont-ils pas domestiqué le pécari? In Bruno Latour \& Pierre Lemonnier (eds.), De la préhistoire aux missiles balistiques: L'intelligence sociale des techniques, 329-44. Paris: Découverte.

Enfield, Nicholas (2007). Transmission biases in linguistic epidemiology. Leipzig: The Max Planck Institute for Evolutionary Anthropology.

Erikson, Philippe (1987). De l'apprivoisement à l'approvisionnement: Chasse, alliance et familiarisation en Amazonie amériendienne. Techniques \& Culture 9:105-40.

Faller, Martina (2002). Semantics and pragmatics of evidentials in Cuzco Quechua. Stanford, CA: Stanford University $\mathrm{PhD}$ dissertation.

Fausto, Carlos (1995). Of enemies and pets: Warfare and shamanism in Amazonia. American Ethnologist 26:933-56.

Floyd, Rick (1999). The structure of evidential categories in Wanka Quechua. Dallas, TX: Summer Institute of Linguistics Publications in Linguistics.

Gal, Susan, \& Judith T. Irvine (2019). Signs of difference: Language and ideology in social life. Cambridge: Cambridge University Press.

Gelman, Rochel, \& Earl M. Williams (1998). Enabling constraints for cognitive development and learning: Domain specificity and epigenesis.. In William Damon (ed.), Handbook of child psychology, vol. 2: Cognition, perception, and language, 575-630. Hoboken, NJ: John Wiley \& Sons.

Gelman, Susan A. (2003). The essential child: Origins of essentialism in everyday thought. New York: Oxford University Press.

(2009). Learning from others: Children's construction of concepts. Annual Review of Psychology 60:115-40.

(2010). Generics as a window onto young children's concepts. In Francis J. Pelletier (ed.), Kinds, things, and stuff: The cognitive side of generics and mass terms, 100-122. New York: Oxford University Press.

$\longrightarrow$, \& John D. Coley (1991). Language and categorization: The acquisition of natural kind terms. In Susan A. Gelman \& James P. Byrnes (eds.), Perspectives on language and cognition: Interrelations in development, 146-96. Cambridge: Cambridge University Press.

Language in Society 50:4 (2021) 


\section{BRUCE MANNHEIM}

Bruce Mannheim; Carmen Escalante; \& Ingrid Sánchez Tapia (2015). Teleological talk in parent-child conversations in Quechua. First Language 35:359-76.

Gentner, Dedre, \& José Medina (1998). Similarity and the development of rules. Cognition 65(2-3):263-97. Goffman, Erving (1979). Footing. Semiotica 25:1-30.

Gopnik, Alison, \& Henry M. Wellman (1994). The theory theory. In Lawrence A. Hirschfeld \& Susan A. Gelman (eds.), Mapping the mind: Domain specificity in cognition and culture, 257-93. Cambridge: Cambridge University Press.

Hill, Jane H., \& Bruce Mannheim (1992). Language and world view. Annual Review of Anthropology 21:382-406.

Hintz, Daniel J., \& Diane M. Hintz (2017). The evidential category of mutual knowledge in Quechua. Lingua 186-187:88-109.

Howard, Rosaleen (2014). From quotative other to quotative self: Evidential usage in Pastaza Quechua. In Janis B. Nuckolls \& Lev Michael (eds.), Evidentiality in interaction, 75-101. Amsterdam: John Benjamins.

Huayhua, Margarita (2021). On the road of life: Social oppression in the southern Andes. Dartmouth: University of Massachusetts, ms.

Keane, Webb (2006). Signs are not the garb of meaning: On the social analysis of material things. In Daniel Miller (ed.), Materiality, 182-205. Durham, NC: Duke University Press.

Keil, Frank C. (1991). Theories, concepts, and the acquisition of word meaning. In Susan A. Gelman \& James P. Byrnes (eds.), Perspectives on language and cognition: Interrelations in development, 197221. Cambridge: Cambridge University Press.

Krifka, Manfred (1995). Focus and the interpretation of generic sentences. In Carlson \& Pelletier, $238-64$. Krifka, Manfred; Francis J. Pelletier; Gregory N. Carlson; Allice ter Meulen; Gennaro Chierchia; \& Godehard Link (1995). Genericity: An introduction. In Carlson \& Pelletier, 1-124.

Lempert, Michael (2014). Imitation. Annual Review of Anthropology 43:379-95.

Leslie, Sarah-Jane (2007). Generics and the structure of the mind. Philosophical Perspectives 21(1):375-403.

(2008). Generics: Cognition and acquisition. Philosophical Review 117(1):1-47.

(2012). Generics articulate default generalizations. Recherches Linguistiques de Vincennes $41: 25-44$.

(2017). The original sin of cognition: Fear, prejudice, and generalization. Journal of Philosophy 114:393-421.

— \& Susan A. Gelman (2012). Quantified statements are recalled as generics: Evidence from preschool children and adults. Cognitive Psychology 64:186-214.

- \& Adam Lerner (2016). Generic generalizations. Stanford encyclopedia of philosophy. Online: https://plato.stanford.edu/entries/generics/; accessed August 14, 2020.

Lewis, David K. (1969). Convention: A philosophical study. Cambridge, MA: Harvard University Press.

Lucy, John (ed.) (1993). Reflexive language: Reported speech and metapragmatics. Cambridge: Cambridge University Press.

(1997). Linguistic relativity. Annual Review of Anthropology 26:291-312.

Lyons, John (1977). Semantics. Cambridge: Cambridge University Press.

Malinowski, Bronisław (1935). Coral gardens and their magic: A study of the methods of tilling the soil and of agricultural rites in the Trobriand islands. Vol. 2: The language of magic and gardening. New York: American Book Company.

Mannheim, Bruce (1984). Popular song, popular grammar, poetry, and metalanguage. Word 37:45-75. (1987). Couplets and oblique contexts: The social organization of a folksong. Text 7:265-88.

(1991). The language of the Inka since the European invasion. Austin: University of Texas Press.

(1998). 'Time, not the syllables, must be counted': Quechua parallelism, word meaning, and cultural analysis. Michigan Discussions in Anthropology 13:238-81.

(2018). Preliminary disciplines. Signs and Society 6:111-19. 


\section{THE SOCIAL LIFE OF GENERICS}

(2019). Three axes of variability in Quechua: Regional diversification, contact with other indigenous languages, and social enregisterment. In Linda J. Seligmann \& Kathleen Fine-Dare (eds.), The Andean world, 507-23. Milton Park: Routledge.

(2020). Southern Quechua ontology. In Steven Kosiba, Thomas Cummins, \& John Janusek (eds.), Sacred matter: Animism and authority in the Americas, 371-98. Cambridge, MA: Harvard University Press for Dumbarton Oaks.

_- ; Susan A. Gelman; Carmen Escalante; Margarita Huayhua; \& Rosalía Puma (2011). A developmental analysis of Quechua generics. Language Learning and Development 7:1-23.

, \& Margarita Huayhua (2016). El quechua es un idioma multi-registral. In Anael Pilares, (ed.), Dilemas de la gobernabilidad en el Sur Andino al 2021, 152-56. Cusco: Centro de Estudios Regionales Andinos 'Bartolomé de las Casas'.

\& Guillermo Salas Carreño (2015). Wak'a: Entifications of the Andean sacred. In Tamara Bray (ed.), The archaeology of Wak'as: Explorations of the sacred in the pre-Columbian Andes, 46-72. Boulder: University of Colorado Press.

Markman, Arthur B., \& Dedre Gentner (1997). The effects of alignability on memory. Psychological Science 8(5):363-67.

McConnell-Ginet, Sally (2012). Generic predicates and interest relativity. Canadian Journal of Linguistics 57(2):289-302.

(2020). Words matter: Meaning and power. Cambridge: Cambridge University Press.

Medin, Douglas L., \& Andrew Ortony (1989). Psychological essentialism. In Stella Vosniadou \& Andrew Ortony (eds.), Similarity and analogical reasoning, 179-95. New York: Cambridge University Press.

Murphy, Gregory L., \& Douglas L. Medin (1985). The role of theories in conceptual coherence. Psychological Review 92:289-316.

Norton, Marcy (2015). The chicken or the iegue: Human-animal relationships and the Columbian exchange. American Historical Review 120:18-60.

Nuckolls, Janis B. (2008). Deictic selves and others in Pastaza evidential usage. Anthropological Linguistics 50:67-89.

Orvell, Ariana; Ethan Kross; \& Susan A. Gelman (2017). How 'you’ makes meaning. Science 355:1299_ 1302.

Prasada, Sandeep (2000). Acquiring generic knowledge. Trends in Cognitive Sciences 4:66-72.

— \& Elaine M. Dillingham (2009). Representation of principled connections: A window onto the formal aspect of common sense conception. Cognitive Science 33:401-48.

Rooth, Mats (1995). Indefinites, adverbs of quantification and focus semantics. In Carlson \& Pelletier, 238-64.

(1996). Focus. In Shalom Lappin (ed.), The handbook of contemporary semantic theory, 271-97. London: Blackwell.

Salas Carreño, Guillermo (2019). Lugares parientes: Comida y cohabitación en la emergencia de mundos Andinos. Lima: Fondo Editorial de la Pontificia Universidad Católica del Perú.

Silverstein, Michael (1976). Hierarchy of features and ergativity. In Robert M. W. Dixon (ed.), Grammatical categories in Australian languages, 112-71. Canberra: Australian National University.

(1993). Metapragmatic discourse and metapragmatic function. In Lucy, 33-58.

Simons, Daniel J., \& Frank C. Keil (1995). An abstract to concrete shift in the development of biological thought: The insides story. Cognition 56:129-63.

Sperber, Dan (1985). Anthropology and psychology: Towards an epidemiology of representations. Man 20:73-89.

van der Wal, Jenneke (2016). Diagnosing focus. Studies in Language 40:259-301.

Wellman, Henry M., \& Susan A. Gelman (1998). Knowledge acquisition in foundational domains. In Deanna Kuhn \& Robert S. Siegler (eds.), Handbook of child psychology, vol 2: Cognition, perception and language, 5th edn., 523-73. New York: Wiley. 


\section{BRUCE MANNHEIM}

Woolard, Kathryn A. (1998). Language ideology as a field of inquiry. In Bambi B. Schieffelin, Kathryn A. Woolard, \& Paul V. Kroskrity (eds.), Language ideologies: Practice and theory, 3-47. New York: Oxford University Press.

(Received 16 August 2020; revision received 10 March 2021; accepted 21 March 2021; final revision received 23 March 2021)

Address for correspondence: Bruce Mannheim Department of Anthropology University of Michigan Ann Arbor, MI 48109-1107, USA mannheim@umich.edu 